\title{
A novel and simple technique for correction of posterior leaflet prolapse due to chordal elongation or rupture
}

\author{
Antonio M. Calafiore, MD, ${ }^{\mathrm{a}}$ Angela L. Iacò, MD, ${ }^{\mathrm{a}}$ Adam Ibrahim, MD, ${ }^{\mathrm{a}}$ Hussein Al-Amri, MD, \\ Reda Refaie, MD, ${ }^{\mathrm{a}, \mathrm{c}}$ Ali Own, MD, ${ }^{\mathrm{a}}$ El Shurafa Heytham, MD, ${ }^{\mathrm{b}}$ and Michele Di Mauro, MD ${ }^{\mathrm{d}}$
}

Objective: The study objective was to evaluate the midterm results of a technique for correction of posterior leaflet prolapse without resection or use of artificial chordae.

\begin{abstract}
Methods: From May 2009 to October 2013, 96 patients with isolated posterior leaflet prolapse $(\mathrm{n}=36)$ or bileaflet prolapse $(n=60)$ with or without chordal rupture underwent posterior leaflet repair at the Prince Sultan Cardiac Center. The novel Uniscallop ("U") technique was used in 46 patients (group U), based only on scallop suture without resection or artificial chordae application. A conventional approach (quadrangular or triangular resection, focal sliding, artificial chordae) was adopted in the remaining 50 patients (group C). In both groups, the annulus was reshaped using a 40- or 50-mm-long band. Postoperative echocardiography was performed in all patients after a mean follow-up of $18 \pm 13$ months in group $\mathrm{U}$ and $20 \pm 9$ months in group $\mathrm{C}$.
\end{abstract}

Results: There were no early or late deaths. No patients in either group showed systolic anterior motion. Both surgical strategies were successful in obtaining a significant reduction in mitral regurgitation grade. Left ventricular function was maintained, and tricuspid regurgitation grade was reduced overall. Moderate mitral regurgitation during follow-up developed in only 1 patient in group $\mathrm{C}$, as the result of dehiscence of a plication stitch.

Conclusions: Although the rationale for the use of the $\mathrm{U}$ technique is different from what is generally accepted, the midterm results of this approach are comparable to those obtained with more conventional techniques, remaining stable after a mean follow-up of 18 months. (J Thorac Cardiovasc Surg 2014;148:1407-12)

Supplemental material is available online.

Over-reduction of the mitral annulus is commonly used for the surgical treatment of functional mitral regurgitation (MR). In 2006, we proposed to adopt the same concept in mitral valve (MV) repair for degenerative disease. ${ }^{1}$ In that report, correction of posterior leaflet (PL) prolapse was performed using conventional techniques, including quadrangular resection with focal sliding, ${ }^{2}$ artificial neochordae application, and edge-to-edge repair. With time, we realized that correction of PL prolapse with or without chordal rupture could be achieved by suturing all the scallops together, after reducing excess leaflet height, if any. Annular over-reduction was the final step of the procedure.

\footnotetext{
From the Departments of Adult Cardiac Surgery, ${ }^{\mathrm{a}}$ and Adult Cardiology, ${ }^{\mathrm{b}}$ Prince Sultan Cardiac Center, Riyadh, Saudi Arabia; Department of Cardiothoracic Surgery, ${ }^{c}$ Mansoura University, Mansoura, Egypt; and Institute of Cardiology, ${ }^{\mathrm{d}}$ University of L'Aquila, L'Aquila, Italy.

Disclosures: Authors have nothing to disclose with regard to commercial support.

Presented at the 2014 Florida Valve International Symposium, Miami, Florida, March 7-9, 2014.

Received for publication Nov 7, 2013; revisions received Jan 26, 2014; accepted for publication Feb 14, 2014; available ahead of print March 27, 2014.

Address for reprints: Antonio Maria Calafiore, MD, Department of Adult Cardiac

Surgery, Prince Sultan Cardiac Center, Riyadh, Saudi Arabia (E-mail: am. calafiore@gmail.com).

$0022-5223 / \$ 36.00$

Copyright (c) 2014 by The American Association for Thoracic Surgery

http://dx.doi.org/10.1016/j.jtcvs.2014.02.046
}

We report the midterm results of this procedure comparing the echocardiographic results with those obtained by using a more conventional technique during the same time frame.

\section{MATERIAL AND METHODS}

From May 2009 to October 2013, 96 patients with isolated PL prolapse ( $n=36)$ or bileaflet prolapse $(n=60)$ with or without chordal rupture underwent PL repair at the Prince Sultan Cardiac Center. There has been a progressive modification of the surgical technique, with a switch from the conventional approach (resection with focal sliding or use of artificial chordae in addition to scallop suturing and longitudinal plication, if required) to a novel technique (without resection or use of artificial chordae) that we have called the Uniscallop ("U") technique. Patients were divided into 2 groups according to the surgical technique used.

Preoperative data are reported in Table 1. Patients in both groups were similar, because in general, patients with MV prolapse have common characteristics. The institutional review board approved the study and waived patient consent.

\section{Surgical Technique}

All patients underwent surgery with a median sternotomy. Perioperative transesophageal echocardiography was obtained in all patients. Patients treated with the conventional technique (group C) underwent operation as previously described. ${ }^{1}$ In group U, our strategy aimed at the correction of PL prolapse without resection or use of artificial chordae, and with leaflet fixation in vertical position, changing a bileaflet valve into a unileaflet one. This goal was achieved through the following steps.

Modification of posterior leaflet height. In group C, 1 or more U-sutures (4-0 Prolene) were used for longitudinal plication of the scallop(s) to reduce PL height if exceeding $15 \mathrm{~mm} .^{3}$ In group $\mathrm{U}$, height 


$$
\begin{aligned}
& \text { Abbreviations and Acronyms } \\
& \begin{aligned}
\mathrm{AL} & =\text { anterior leaflet } \\
\mathrm{MR} & =\text { mitral regurgitation } \\
\mathrm{MV} & =\text { mitral valve } \\
\mathrm{PL} & =\text { posterior leaflet } \\
\mathrm{SAM} & =\text { systolic anterior motion } \\
\text { "U" } & =\text { Uniscallop }
\end{aligned}
\end{aligned}
$$

reduction was aimed at making the height of the scallops uniform to change the PL from a multiscalloped to a single scalloped leaflet (Figure 1).

Change of posterior leaflet from a multiscalloped to a single scalloped leaflet. Once the height is similar, all scallops are sutured together (4-0 Prolene) to prevent excess leaflet motion at the level where chordal elongation is more pronounced and to limit total PL movement to the portion with a lower degree of chordal elongation (Figure 1). If the prolapse involves all scallops, suturing allows us to consider the PL as a whole and not composed of different segments, independently of any prolapse grade. Scallops are identified by the indentations, which sometimes can be less evident, because they can be of different length.

In patients with chordal rupture, the donor scallop (ie, the scallop with normal or elongated chordae close to the one with ruptured chordae) is positioned below the receiving scallop (ie, the scallop with ruptured chordae) to support it. The rim of the receiving scallop is then sutured to the body of the donor scallop (Figure 2). It is worth noting that the portion of a scallop without chordae will not cause leaflet prolapse, and thus $\mathrm{MR}$, if it is $10 \mathrm{~mm}$ or less.

Annular over-reduction. The MV annulus is reshaped using a 40-mm (SMB40) or 50-mm (SMB50) band. The band is flexible, made of radiopaque silicone core, and covered by a knitted polyester fabric coated with Carbofilm (Sorin, Saluggia, Italy). It is inserted from trigone to trigone using multiple imbricated U-sutures to reduce the stress on the annulus. The septal lateral distance obtained is, as a mean, $21 \mathrm{~mm}^{4}$ for the SMB40 and $24 \mathrm{~mm}$ for the SMB50. The choice of the band depends on the anterior leaflet (AL) length. Because the purpose of the correction is to obtain a coaptation length of $5 \mathrm{~mm}$ or greater, the SMB40 or SMB50 is used if the AL length is less than $30 \mathrm{~mm}$ or $30 \mathrm{~mm}$ or more, respectively. The use of these bands is aimed at moving the posterior annulus toward the anterior annulus pivoting on 2 fixed points (the trigones). The PL is then attracted posteriorly with subsequent increased tethering on PL chords, eliminating the possibility of prolapse. The PL then remains fixed in the vertical position and becomes a buttress for the AL. Anatomic systolic anterior motion (SAM) of the AL cannot occur because the 2 leaflets meet at the extremity of the mitral area.

Anterior leaflet prolapse. In patients with associated AL prolapse, 2 or more artificial chordae (polytetrafluoroethylene; 4-0 Gore-Tex, WL Gore \& Associates, Inc, Flagstaff, Ariz) are used. The length of neochordae is adjusted as previously described. ${ }^{5}$ Any deviant cusp, if present, is sutured with the main body of the leaflet.

Tricuspid regurgitation. Correction of moderate or greater tricuspid regurgitation was performed in all patients, if present, whereas correction of mild tricuspid regurgitation was performed only in patients with annular enlargement.

\section{Echocardiographic Evaluation}

All patients underwent standard preoperative echocardiography. MR was graded as mild (grade 1), moderate (grade 2), moderate to severe (grade 3), and severe (grade 4) according to different parameters, including regurgitant jet area and its ratio to the left atrial area, number and direction of regurgitant jets, and vena contracta width. Ejection fraction was calculated using a modified Simpson's biplane method. The severity of tricuspid regurgitation, as assessed by Doppler echocardiography, was graded on a scale from 1 to 4 (1, mild; 2, moderate; 3, moderate to severe; 4, severe). Pulmonary artery systolic pressure was estimated as the sum of the gradient across the tricuspid valve (calculated from the simplified Bernoulli equation) and the right atrial pressure. The latter was estimated using inferior vena cava size and response to respiration in the subcostal view.

\section{Statistical Analysis}

Results are expressed as mean value \pm standard deviation, unless otherwise indicated. Statistical analysis comparing 2 independent groups was performed with unpaired 2-tailed Student $t$ test for the means or chisquare test for categoric variables. Preoperative and postoperative data were compared with paired 2-tailed Student $t$ test. SPSS software (SPSS Inc, Chicago, Ill) was used for statistical analysis.

\section{RESULTS}

Operative data and surgical techniques for both groups are reported in Table 2. The PL had 3 scallops in 67 patients $(69.8 \%), 2$ scallops in 13 patients (13.5\%), 4 scallops in 15 patients $(15.6 \%)$, and 6 scallops in 1 patient $(1.1 \%)$. A deviant cusp in the AL was present in $28.3 \%$ of cases $(\mathrm{n}=17)$. No patient died within 30 days of surgery or during follow-up. All patients underwent echocardiography postoperatively. There was no or trivial residual MR in all but 1 patient in group $\mathrm{W}$, who required a second pump run with successful correction of MR, which was due to intermittent tethering of second-order chords of the $\mathrm{AL}{ }^{6}{ }^{6}$ Cardiopulmonary bypass and crossclamp times were significantly shorter in group $U$ as a result of the simplicity of the surgical technique.

After a mean follow-up of $19 \pm 11$ months, all patients underwent transthoracic echocardiography. Length of follow-up was not significantly different between groups (mean, $18 \pm 13$ [2-36] months in group U; mean, $20 \pm 9$ [3-38] months in group C; $P=.3799$ ).

Postoperative echocardiographic data are reported in Table 3. Both strategies were successful in obtaining a significant reduction in MR. The final aspect of the MV was comparable for all techniques (Figure E1). Left ventricular function was maintained, and tricuspid regurgitation grade was overall reduced. Residual MR grade was lower in group $\mathrm{U}(0.2 \pm 0.4$ vs $0.4 \pm 0.5, P=.0340)$, because a patient in

TABLE 1. Preoperative data

\begin{tabular}{lccr}
\hline & Group U $(\mathbf{n}=\mathbf{4 6})$ & Group C $(\mathbf{n}=\mathbf{5 0})$ & $\boldsymbol{P}$ value \\
\hline Age $(\mathrm{y})$ & $38 \pm 17$ & $37 \pm 13$ & .7457 \\
Female gender & 29 & 22 & .0618 \\
NYHA class & $2.3 \pm 0.8$ & $2.0 \pm 1.0$ & .3448 \\
Atrial fibrillation & 0 & 0 & 1.0000 \\
Barlow disease & 19 & 17 & .3507 \\
Bileaflet prolapse & 32 & 28 & .4602 \\
PL chordal rupture & 10 & 4 & .0567 \\
\hline
\end{tabular}

NYHA, New York Heart Association; $P L$, posterior leaflet. 

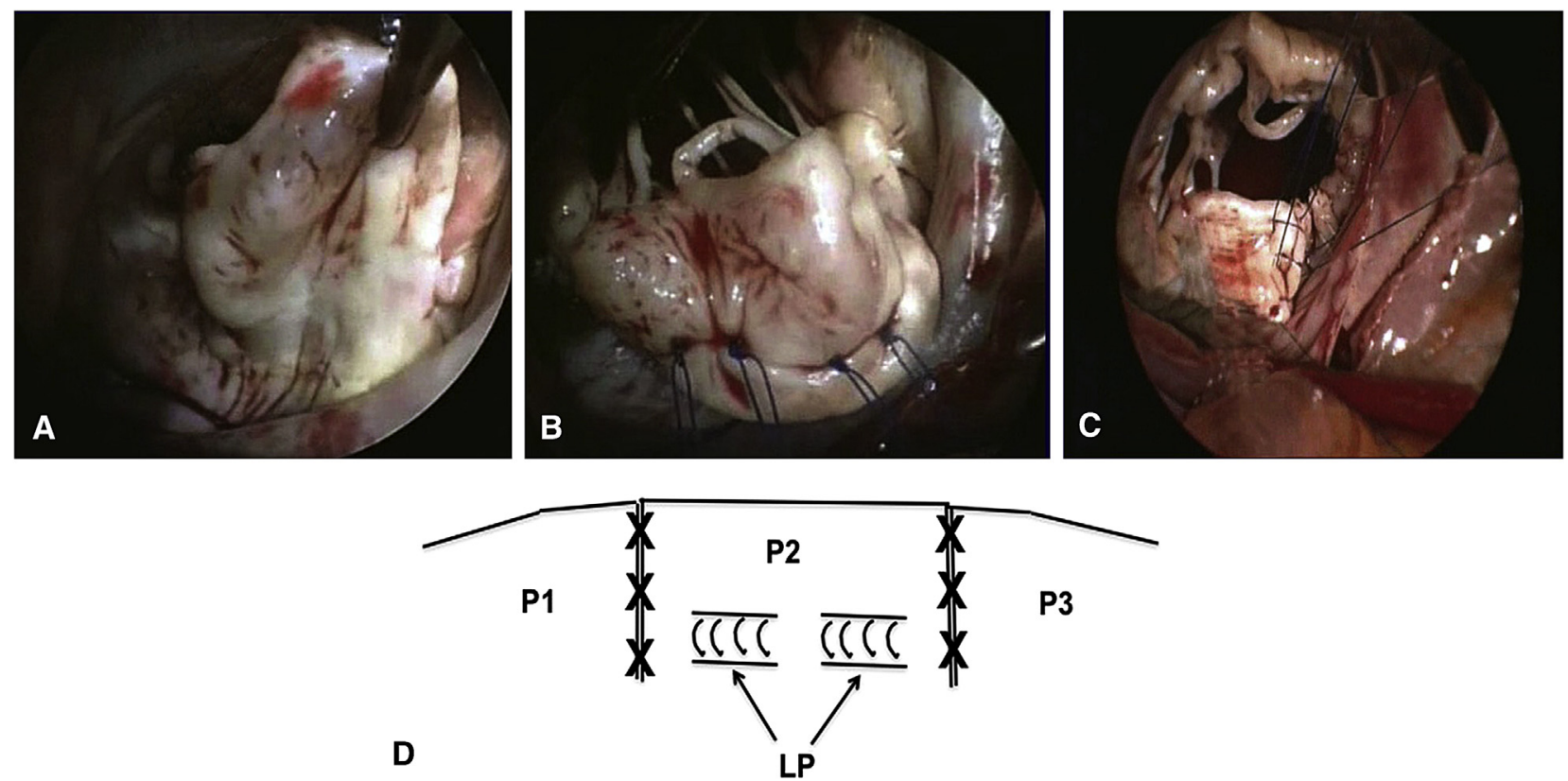

FIGURE 1. A, P2 is longer than normal. B, P2 length is reduced using 4 longitudinal sutures to match the height of the PL scallops. C, The scallops are sutured together with interrupted sutures. D, Schematic vision of the final results. $L P$, Longitudinal plication; $P L$, posterior leaflet.

group $\mathrm{C}$ had moderate MR during follow-up as a result of dehiscence of a plication stitch.

\section{DISCUSSION}

Although repair is the treatment of choice for MV prolapse, incidence of repair in the real world is approximately $70 \%$ of the total number of procedures. ${ }^{7}$ The percentage can be higher or lower, depending on the level of specific expertise. PL prolapse is the most common finding in patients with degenerative MV disease and often can be isolated. Surgical techniques include P2 quadrangular or triangular resection, annular plication, sliding plasty or focal sliding, and use of artificial chordae. Results are good and relatively stable. However, at least $10 \%$ of patients, among whom some underwent surgery but were asymptomatic, show recurrent MR (grade 3 or $4+$ ) at 10 years from surgery. ${ }^{8}$ In the experience of David and colleagues, ${ }^{9}$ freedom from moderate or severe MR in patients who had MV repair for isolated PL prolapse was $80 \% \pm 4 \%$ at 12 years.

With time, there has been an evolution of surgical techniques. Nonresecting techniques have been part of the therapeutic armamentarium of all surgeons, but the possibility of repairing PL prolapse only with artificial chordae was first emphasized by Perier and colleagues. ${ }^{10}$ These authors reported the long-term results of 225 patients $(21.5 \%$ of all those undergoing operation during the study period) undergoing repair of PL prolapse with the "respect rather than resect" approach. The use of nonresecting techniques was based on the surgeon's choice.
Several authors have suggested different approaches to correction of PL prolapse that do not involve partial or complete scallop resection. ${ }^{11-15}$ In a series published by our group in 2006, ${ }^{1}$ nonresecting techniques also were used in 40 patients, including application of artificial chordae when P2 insertion was longer than one third of the posterior MV annulus $(\mathrm{n}=28)$ and longitudinal plication of the scallops $(n=11)$. In a later study comparing resecting with nonresecting techniques, we observed similar results with both approaches. ${ }^{16}$

The main finding of our study is that PL prolapse can be corrected only by annular over-reduction associated with scallop suturing and, if necessary, longitudinal plication of the scallops for height adjustment. The elements of this technique are not new, and all of them are used in selected cases, but we demonstrated that they are enough to correct PL prolapse. If chordae are elongated, the suture line is at the level of the adjacent free rims of the scallops. If the chordae are ruptured, the donor scallop is positioned below the receiving scallop and the suture line connects the rim of the receiving scallop with the body of the donor scallop (Figure 2). The only precaution is to leave $10 \mathrm{~mm}$ or less of free margin without chordae. If chordal rupture involves the portion of $\mathrm{P} 1$ or $\mathrm{P} 3$ segments close to the commissure, it is commonly treated by obliterating the commissure. The only limit to this strategy is the rare event when all PL chordae are torn. Although we never encountered such a case, artificial neochordae application may be the only solution.

Over-reduction of the mitral annulus is part of the strategy we described. The implant of a short band from 
P3

P2

P1

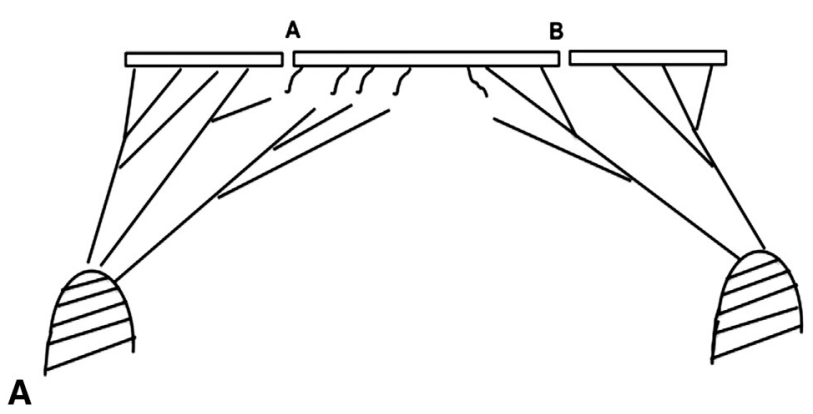

P2 P1

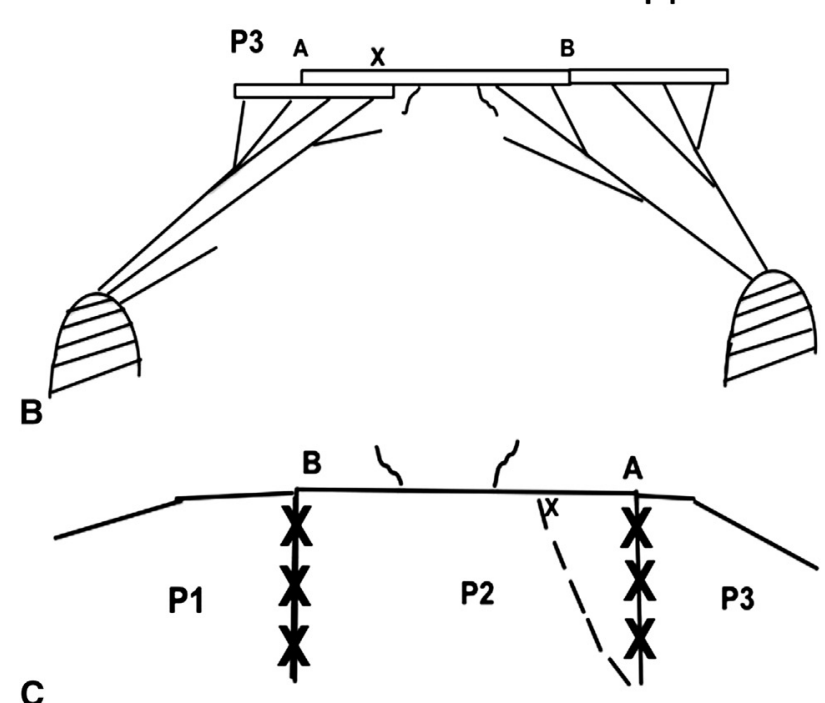

FIGURE 2. A, P2 chordae are ruptured, mostly close to $\mathrm{P} 3$. B and C, $\mathrm{P} 3$ is sutured below P2 so its chordae will support part of P2. A portion of $\mathrm{P} 2$ remains without chordae. $\mathrm{x}$, This suture will define the position of $\mathrm{P} 3$ below $\mathrm{P} 2$.

trigone to trigone is able to reproduce what is performed in functional MR surgery, changing a bileaflet valve into a unileaflet valve. This goal can be achieved with devices that reshape the mitral annulus, provided the same strategy (over-reduction) is applied. It is crucial to avoid PL movement to prevent the occurrence of SAM, because MV leaflets meet at the border rather than inside the mitral annular area. Of 52 patients $(6.6 \%)$ in whom SAM developed, Varghese and colleagues ${ }^{17}$ found that the PL was involved in $49(94.2 \%)$. This complication is relatively frequent after MV repair. In the retrospective study of Brown and colleagues, ${ }^{18}$ SAM was identified in $8.4 \%$ of cases at the end of the procedure, decreasing to $3 \%$ at discharge. At a median follow-up of 5.4 years, $18.3 \%$ of patients in whom SAM developed intraoperatively still showed this complication. However, SAM virtually does not occur after MV repair for functional MR, and we applied the same concept (PL verticalization) to minimize or eliminate this frustrating complication.
TABLE 2. Operative findings and surgical strategies

\begin{tabular}{lccc}
\hline & Group U $(\mathbf{n}=\mathbf{4 6})$ & Group C $(\mathbf{n}=\mathbf{5 0})$ & $\boldsymbol{P}$ value \\
\hline Longitudinal plication & 17 & 23 & .8848 \\
PL scallop suture & 46 & 31 & .0000 \\
PL scallop sliding & 10 & 0 & .0005 \\
AL scallop suture & 9 & 8 & .6476 \\
PL resection & 0 & 7 & .0084 \\
Annular plication & 0 & 4 & .0500 \\
Focal sliding & 0 & 4 & .0500 \\
Chordae on PL/patient & 0 & $4.8 \pm 1.4(\mathrm{n}=43)$ & .0000 \\
Chordae on AL/patient & $4.6 \pm 1.1(\mathrm{n}=32)$ & $5.7 \pm 1.5(\mathrm{n}=28)$ & .0036 \\
TV repair & 15 & 25 & .0842 \\
Miniband 40 & 40 & 43 & .8912 \\
Miniband 50 & 6 & 7 & \\
CPB time (min) & $81 \pm 24$ & $96 \pm 21$ & .0015 \\
Crossclamp time (min) & $65 \pm 21$ & $83 \pm 30$ & .0011 \\
ICU stay (d) & $2.0 \pm 2.1$ & $1.9 \pm 1.2$ & .7730 \\
In-hospital stay (d) & $11 \pm 10$ & $9 \pm 7$ & .2561 \\
\hline$A L$, Anterior leaflet; $C P B$, cardiopulmonary bypass; $I C U$, intensive & care unit; \\
$P L$, posterior leaflet; $T V$, tricuspid valve. & &
\end{tabular}

It is worth discussing the possibility that mitral stenosis may occur postoperatively. Several studies demonstrated significant gradients, at rest or on effort, after overreduction of the mitral annulus for functional MR. ${ }^{19,20}$ Although there is no general consensus on this issue, we believe that a different situation exists when applying the same concept to correction of PL prolapse. When a 40- or 50 - $\mathrm{mm}$-long band is implanted from trigone to trigone with an intertrigonal distance of approximately $25 \mathrm{~mm}$, mitral annular circumference is such to generate a theoretic anatomic orifice of 3.0 to $4.5 \mathrm{~cm}^{2}$. The mean functional area is slightly less than $3.5 \mathrm{~cm}^{2}$ (Table 3), because left ventricular end-diastolic pressure, being low, causes high diastolic gradient and high transmitral flow. In addition, the AL is in its physiologic preopening position (from $20^{\circ}$ to $25^{\circ}$ ), thus minimizing the opening velocity. As a result, the MV will function normally both at rest and during effort. The situation is different after annular over-reduction for functional MR. Left ventricular end-diastolic pressure can be higher than normal, the velocity of AL opening will be lower, and functional MV area can be affected by the different underlying disease. As a consequence, functional mitral stenosis can be observed in some cases, although its impact on long-term outcome seems to be limited. ${ }^{21}$ Our patients had low rest gradients across the MV and were asymptomatic in their daily life. In a recent study, Mesana and colleagues $^{22}$ reported that mean gradients are smaller in patients in whom a band was used to repair degenerative MV prolapse, and their results agree with our findings.

\section{Study Limitations}

Patients were not randomized, and the use of the $\mathrm{U}$ technique was adopted progressively until the moment it became the technique of choice for correction of PL 
TABLE 3. Echocardiographic findings

\begin{tabular}{|c|c|c|c|c|c|c|c|}
\hline & \multicolumn{3}{|c|}{ Group U $(n=46)$} & \multicolumn{3}{|c|}{ Group C $(\mathbf{n}=\mathbf{5 0})$} & \multirow[b]{2}{*}{$P$ value* } \\
\hline & Pre & Post & $P$ value & Pre & Post & $P$ value & \\
\hline $\mathrm{EF}(\%)$ & $53 \pm 6$ & $54 \pm 3$ & .2986 & $55 \pm 7$ & $55 \pm 8$ & 1.0000 & .4272 \\
\hline $\mathrm{EDD}(\mathrm{mm})$ & $52 \pm 5$ & $44 \pm 4$ & .0000 & $54 \pm 5$ & $44 \pm 6$ & .0000 & 1.0000 \\
\hline $\mathrm{ESD}(\mathrm{mm})$ & $33 \pm 5$ & $27 \pm 6$ & .0000 & $35 \pm 6$ & $29 \pm 7$ & .0003 & .1378 \\
\hline MR grade $(0-4)$ & $3.8 \pm 0.6$ & $0.2 \pm 0.4$ & .0000 & $3.7 \pm 0.7$ & $0.4 \pm 0.5$ & .0000 & .0340 \\
\hline MV gradient $(\mathrm{mm} \mathrm{Hg})$ & & $3.2 \pm 0.9$ & & & $3.4 \pm 1.0$ & & .3072 \\
\hline MV functional area $\left(\mathrm{cm}^{2}\right)$ & - & $3.4 \pm 0.5$ & & - & $3.3 \pm 0.7$ & & .4262 \\
\hline TR grade & $1.2 \pm 0.9$ & $0.2 \pm 0.4$ & .0000 & $1.3 \pm 1.0$ & $0.3 \pm 0.5$ & .0000 & .2847 \\
\hline TV gradient & & $2.4 \pm 0.6$ & & & $2.6 \pm 0.5$ & & .0784 \\
\hline PAPs (mm Hg) & $32 \pm 12$ & $28 \pm 10$ & .0784 & $35 \pm 10$ & $31 \pm 11$ & .0662 & 1666 \\
\hline
\end{tabular}

$E D D$, End-diastolic volume; $E F$, ejection fraction; $E S D$, end-systolic volume; $M R$, mitral regurgitation; $M V$, mitral valve; $P A P s$, pulmonary artery systolic pressure; $T R$, tricuspid regurgitation; $T V$, tricuspid valve. *Post $\mathrm{U}$ versus post $\mathrm{C}$.

prolapse. However, the $\mathrm{U}$ technique was used for up to 4 years at the time of the study, and we were able to apply it to all patients, including those with Barlow disease. During this time frame, the most relevant aspect was the possibility for the younger surgeons to learn how to correct bileaflet prolapse with optimal early and midterm results. However, a different technique is not a guarantee of a better outcome, especially if compared with the excellent results of more conventional procedures. Even if after an 18-month follow-up the residual MR grade was lower with the $\mathrm{U}$ technique, we have to wait for a longer follow-up to know whether this technique has its place in the surgical treatment of PL prolapse of the MV.

\section{CONCLUSIONS}

An increasingly better understanding of the pathophysiology of PL prolapse has led to the introduction of new surgical options for the correction of this disease. We are aware that the bar for repairing PL prolapse or chordal rupture is high and that good results can be obtained using conventional techniques. Nevertheless, there is always space for a surgical strategy different from the wellestablished ones, especially if it is easy to perform and prevents SAM, a well-known complication of MV prolapse repair. The midterm results of the $\mathrm{U}$ technique are good and comparable to those obtained with more conventional techniques. Echocardiographic results are stable, but a longer follow-up is needed to evaluate the impact of this technique on the incidence of the late development of moderate or severe MR.

\section{References}

1. Calafiore AM, Di Mauro M, Iacò AL, Mazzei V, Teodori G, Gallina S, et al. Overreduction of the posterior annulus in surgical treatment of degenerative mitral regurgitation. Ann Thorac Surg. 2006;81:1310-6.

2. Grossi EA, Galloway AC, Kallenbach K, Miller JS, Esposito R, Schwartz DS, et al. Early results of posterior leaflet folding plasty for mitral valve reconstruction. Ann Thorac Surg. 1998;65:1057-9.

3. Calafiore AM, Di Mauro M, Actis-Dato G, Iacò AL, Centofanti P, Forsennati P, et al. Longitudinal plication of the posterior leaflet in myxomatous disease of the mitral valve. Ann Thorac Surg. 2006;81:1909-10.
4. Calafiore AM, Iacò AL, Bivona A, Varine E, Scandura S, Greco P, et al. Echocardiographically based treatment of chronic ischemic mitral regurgitation. J Thorac Cardiovasc Surg. 2011;141:1150-6.e1.

5. Calafiore AM, Scandura S, Iacò AL, Contini M, Di Mauro M, Bivona A, et al. A simple method to obtain the correct length of the artificial chordae in complex chordal replacement. J Card Surg. 2008;23:204-6.

6. Iacò AL, Ahmed AA, Al Zaharani G, Al Amri H, Di Mauro M, Calafiore AM. Intermittent tethering of second-order chords after mitral valve repair for bileaflet prolapsed. Ann Thorac Surg. 2013;96:e145-6.

7. Daneshmand MA, Milano CA, Rankin JS, Honeycutt EF, Shaw LK, Davis RD, et al. Influence of patient age on procedural selection in mitral valve surgery. Ann Thorac Surg. 2010;90:1479-86.

8. Johnston DR, Gillinov AM, Blackstone EH, Griffin B, Stewart W, Sabik JF III et al. Surgical repair of posterior mitral valve prolapse: implications for guidelines and percutaneous repair. Ann Thorac Surg. 2010;89:1385-94.

9. David TE, Ivanov J, Armstrong S, Christie D, Rakowski H. A comparison of outcomes of mitral valve repair for degenerative disease with posterior, anterior, and bileaflet prolapse. J Thorac Cardiovasc Surg. 2005;130: 1242-9.

10. Perier P, Hohenberger W, Lakew F, Batz G, Urbanski P, Zacher M, et al. Toward a new paradigm for the reconstruction of posterior leaflet prolapse: midterm results of the "respect rather than resect" approach. Ann Thorac Surg. 2008;86:718-25.

11. Tabata M, Ghanta RK, Shekar PS, Cohn LH. Early and midterm outcomes of folding valvuloplasty without leaflet resection for myxomatous mitral valve disease. Ann Thorac Surg. 2008;86:1388-90.

12. Alfieri O, Maisano F, De Bonis M, Stefano PL, Torracca L, Oppizzi M, et al. The double-orifice technique in mitral valve repair: a simple solution for complex problems. J Thorac Cardiovasc Surg. 2001;122:674-81.

13. Nigro JJ, Schwartz DS, Bart RD, Bart CW, Lopez BM, Cunningham MJ, et al Neochordal repair of the posterior mitral leaflet. J Thorac Cardiovasc Surg. 2004; 127:440-7.

14. Falk V, Seeburger J, Czesla M, Borger MA, Willige J, Kuntze T, et al. How does the use of polytetrafluoroethylene neochordae for posterior mitral valve prolapse (loop technique) compare with leaflet resection? A prospective randomized trial. J Thorac Cardiovasc Surg. 2008;136:1205-6.

15. Seeburger J, Falk V, Borger MA, Passage J, Walther T, Doll N, et al. Chordae replacement versus resection for repair of isolated posterior mitral leaflet prolapsed: a ègalité. Ann Thorac Surg. 2009;87:1715-20.

16. Calafiore AM, Di Mauro M, Iacò AL, Varone E, Romeo A, Mangiafico S, et al Resecting and nonresecting techniques for posterior mitral leaflet prolapse. J Card Surg. 2011;26:119-23.

17. Varghese R, Anyanwu AC, Itagaki S, Milla F, Castillo J, Adams DH. Management of systolic anterior motion after mitral valve repair: an algorithm. J Thorac Cardiovasc Surg. 2012;143(4 Suppl):S2-7.

18. Brown ML, Abel MD, Click RL, Morford RG, Dearani JA, Sundt TM, et al. Systolic anterior motion after mitral valve repair: is surgical intervention necessary? J Thorac Cardiovasc Surg. 2007;133:136-43.

19. Kubota K, Otsuji Y, Ueno T, Koriyama C, Levine RA, Sakata R, et al. Functional mitral stenosis after surgical annuloplasty for ischemic mitral regurgitation: importance of subvalvular tethering in the mechanism and dynamic deterioration during exertion. J Thorac Cardiovasc Surg. 2010;140:617-23. 
20. Kainuma S, Taniguchi K, Daimon T, Sakaguchi T, Funatsu T, Kondoh H, et al. Does stringent restrictive annuloplasty for functional mitral regurgitation cause functional mitral stenosis and pulmonary hypertension? Circulation. 2011; 124(Suppl 1):S97-106.

21. Williams ML, Daneshmand MA, Jollis JG, Horton JR, Shaw LK, Swaminathan M, et al. Mitral gradients and frequency of recurrence of mitral regurgitation after ring annuloplasty for ischemic mitral regurgitation. Ann Thorac Surg. 2009;88:1197-201.

22. Mesana TG, Lam B-K, Chan V, Chen K, Ruel M, Chan K. Clinical evaluation of functional mitral stenosis after mitral valve repair for degenerative disease: potential affect on surgical strategy. J Thorac Cardiovasc Surg. $2013 ; 146: 1418-25$. 

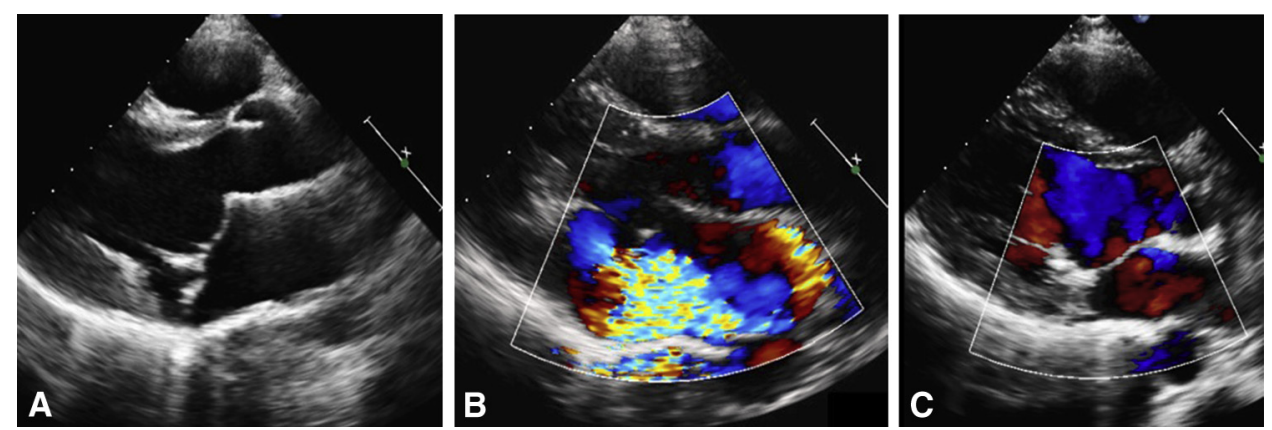

FIGURE E1. Transthoracic echocardiography (short-axis view) in a patient in group U. Bileaflet prolapse (A) causing severe MR (B). C, At 18 months after surgery, there is no evidence of MR. This echocardiographic finding is common to all patients, regardless of the technique used. 